\title{
Embryo Elongation and Germination Rates as Sensitive Indicators of Lettuce Seed Quality: Priming and Aging Studies
}

\author{
G. Hacisalihoglu' , A.G. Taylor ${ }^{2}$, D.H. Paine ${ }^{3}$, M.B. Hilderbrand ${ }^{3}$, and \\ A.A. Khan ${ }^{4}$ \\ Department of Horticultural Sciences, New York State Agricultural \\ Experimental Station, Cornell University, Geneva, NY 14456-0462
}

Additional index words. seed vigor, enhancement, storage, Lactuca sativa, seed testing

\begin{abstract}
High-quality seed lots are required for successful establishment of horticultural crops. Testing methods are needed that can detect the early phases of aging prior to a significant loss in germination. Quality was assessed using both germination speed and uniformity on non-primed and primed, as well as non-aged and aged, lettuce (Lactuca sativa $L$.) seed. Speed and uniformity were quantified using time to $50 \%\left(T_{50}\right)$ germination and one standard deviation $\left(\mathrm{T}_{\mathrm{sd}}\right)$, respectively. Embryo elongation was developed as a rapid test by first soaking seeds for 2 hours, then cutting and removing the distal one-third of the seed, and finally observing the percentage of visibly elongated embryos from the seed coverings over time. The mild aging conditions employed in this study $\left(45{ }^{\circ} \mathrm{C}\right.$ and $50 \%$ relative humidity for up to 21 days) had little influence on viability (germination in all treatments was $>98 \%$ ), but reduced germination rate (increased the time for $T_{50}$ and $T_{s d}$ ). Primed seeds aged faster than non-primed seeds under the same aging conditions. The percentage of elongated embryos was calculated at hourly intervals after cutting, and treatment differences were observed after a total hydration period of 5 hours. The embryo elongation test detected aging in both primed and non-primed treatments.
\end{abstract}

Seed quality is a broad term encompassing several attributes of a seed lot, including germination and vigor potential. High-quality lots are needed for successful germination and seedling performance of horticultural crops; however, aging decreases seed quality. Germination decreases in a sigmoidal manner with storage duration (Priestley, 1986), and the early stages of aging may not be detected by a standard germination test. Therefore, rapid seed quality or vigor tests are needed that are able to detect the early stages of aging prior to a significant loss in the percent germination.

Several physiological and biochemical changes are associated with the loss of germination due to aging (reviewed by Priestly, 1986). At the whole-plant (organism) level, germination rate is the most sensitive indicator of a decline in seed quality (reviewed by Association of Official Seed Analysts, 1983). For example, total percent germination of let-

\footnotetext{
Received for publication 11 Dec. 1998. Accepted for publication 20 May 1999. G. Hacisalihoglu was supported by a graduate student scholarship from The Republic of Turkey. The cost of publishing this paper was defrayed in part by the payment of page charges. Under postal regulations, this paper therefore must be hereby marked advertisement solely to indicate this fact.

${ }^{1}$ Former Graduate Student.

${ }^{2}$ Professor of Seed Science and Technology; to whom reprint requests should be addressed. E-mail: agt1@cornell.edu

${ }^{3}$ Research Technician.

${ }^{4}$ Professor of Seed Physiology, deceased.
}

tuce seeds was unaffected by mild aging, while a 6-h delay in radicle emergence was recorded under the same conditions (Taylor, 1997). Methods have been developed to semi-automate or automate the recording of germination events. A technique termed "time-sequence photography" was described that employs a 35-mm camera equipped with intervalometer and flash (Tomas et al., 1992). A machine vision system can record germination and seedling growth rates (Howarth and Stanwood, 1993). Both techniques produce objective data that can quantify germination rate and uniformity.

Methods that directly evaluate embryo growth have been developed for routine seed testing and for research. The excised embryo technique is a viability test used on woody and other species (International Seed Testing Association, 1996). The embryo is removed from the seed-covering tissue in this technique, which eliminates or reduces exogenous dormancy factors. Embryo excision is widely used as a viability test and is less subjective than tetrazolium testing. Growth (elongation rates) of excised embryos has been used to study dormancy, enhancement treatments, and aging in small-seeded vegetable seeds (Hacisalihoglu, 1997; Hacisalihoglu and Khan, 1998). In these studies, seeds were first imbibed, then a portion of the seed containing the radicle end was excised and the embryo removed from the enclosing seed-covering tissues. The embryo elongation rate was determined from magnified images and growth was recorded for 32 or $48 \mathrm{~h}$, depending on species. The technique was well suited for detailed investigations of embryo growth, but was too cumbersome for use as a rapid seed quality test.

Seed enhancements are postharvest treatments that improve germination and seedling growth, or facilitate the delivery of seeds and other materials required at time of sowing (Taylor et al., 1998). Priming is a common seed enhancement method that accelerates germination (reviewed by Khan, 1992; Taylor et al., 1998). Priming may, however, negatively affect seed longevity. Limited research has been reported on storage of primed seeds, and beneficial, neutral, and deleterious effects of storing primed seeds have been reported (reviewed by Parera and Cantliffe, 1994). In general, high seed quality can be maintained if primed seeds are stored under ideal conditions or stored for a short period of time prior to sowing. For example, primed and non-primed lettuce seeds that were stored for 5 months at $5{ }^{\circ} \mathrm{C}$ with $6 \%$ moisture content exhibited $>95 \%$ germination when germinated at $20^{\circ} \mathrm{C}$ (Valdes and Bradford, 1987). In contrast, primed lettuce seeds stored at $40{ }^{\circ} \mathrm{C}$ with $10 \%$ moisture aged at a faster rate than non-primed seeds (Tarquis and Bradford, 1992). There is general consensus that priming decreases longevity (Taylor et al., 1998).

The objectives of this study were to 1) examine the influence of priming and aging on germination speed and uniformity, 2) quantify water uptake by non-primed and primed seeds, and 3) develop a rapid technique that can be used to quantify embryo elongation to assess priming and aging by quantifying the onset of embryo elongation.

\section{Materials and Methods}

Seed materials and aging. A lettuce seed lot of Waldmann's Green (Pybas Seeds, Salinas, Calif.) was used in all studies. Seeds were either non-primed or primed with a proprietary method developed by Seed Dynamics Inc. (Salinas, Calif.). Seed samples were aged by first equilibrating seeds at $50 \%$ relative humidity (RH) at ambient room temperatures in a closed system as described by Taylor et al. (1997). Relative humidity was maintained with solutions of glycerol and water, and seeds were placed above the solution on $10 \times 10 \mathrm{~cm}$ trays that were fitted with a fine mesh sieve (custom made by Hoffman Manufacturing, Albany, Ore.). Seeds were equilibrated for a period of $7 \mathrm{~d}$ in a closed Plexiglas chamber equipped with a circulation fan, and then the moisture content was determined by the oven method (International Seed Testing Association, 1996). Equilibrated samples were placed in cryovials (Nalge Nunc International, Rokskilde, Denmark) and then heat-sealed in aluminum-plastic envelopes. Samples were aged for $0,7,14$, or $21 \mathrm{~d}$ at $45^{\circ} \mathrm{C}$. Samples were then transferred to refrigerated storage and small batches were removed as needed for specific studies.

Germination test. Non-primed and primed seeds that were aged for $0,7,14$, or $21 \mathrm{~d}$ were placed on two steel blue blotter papers (Anchor Paper, Hudson, Wis.) moistened with 16 $\mathrm{mL}$ of $\mathrm{H}_{2} \mathrm{O}$. Blotters were placed in $11 \times 11-\mathrm{cm}$ 
germination boxes (crispers made of translucent plastic) (Hoffman Manufacturing). The crispers were maintained at a constant $25{ }^{\circ} \mathrm{C}$ with continuous light provided by cool-white fluorescent tubes. The light intensity was $\approx 10$ $\mu \mathrm{mol} \cdot \mathrm{m}^{-2} \cdot \mathrm{s}^{-1}$ (photosynthetic photon flux) as measured by a quantum sensor (Li-cor model Li-185A, Lincoln, Nebr.). Visible radicle protrusion was recorded as the criterion of germination. Counts of germinating seeds were made every hour during the first $24 \mathrm{~h}$ and then at frequent intervals until no further germination occurred, up to $120 \mathrm{~h}$. Germinated seeds were discarded at each count. Each treatment was replicated four times with 50 seeds per replication.

Water uptake. Non-aged primed or nonprimed lettuce seeds were used to quantify water uptake in time course studies. One-gram samples were imbibed by submerging seeds in labeled weigh boats at room temperature $\approx 25$ $\left.{ }^{\circ} \mathrm{C}\right)$. Weight was recorded prior to the addition of water $\left(\mathrm{Wt}_{\mathrm{o}}\right)$ and at hourly intervals up to 5 $h$. At each interval, seeds were removed with a strainer and blotted before weighing. Data was expressed as the weight at a particular imbibition time divided by the initial seed weight $\left(\mathrm{Wt} / \mathrm{Wt}_{\mathrm{o}}\right)$ as described by Hill and Taylor (1989). There were four replications per treatment and standard errors were calculated.

Embryo elongation test. Primed and nonprimed seeds were aged for $0,7,14$, or $21 \mathrm{~d}$ and placed in the same controlled-environment room as the germination test $\left(25^{\circ} \mathrm{C}\right.$ constant with continuous light). The following method was used to assess embryo elongation. Each replicate was placed in individual, labeled weigh boats, and distilled water was added so all seeds were submerged. While the seeds were imbibing, crispers were prepared with one blotter $(10 \times 10-\mathrm{cm}$ steel blue blotter $)$ hydrated with $7 \mathrm{~mL}$ distilled water. Seeds were imbibed for $2 \mathrm{~h}$ and water was decanted. A dry blotter was placed on top of the wet blotter paper in the crisper. The 2-h imbibed seeds were spread on this dry blotter and each seed was cut using a sharp scalpel blade with two-thirds of the radicle end kept, while the remaining one-third (distal portion) was discarded. After seeds were cut, an additional 9 $\mathrm{mL}$ of water was added and the crisper lid was closed. Visible elongation of the embryo beyond the seed coverings was recorded on hourly intervals. The time for embryo elongation included the 2-h water soak.

There were four replications per treatment with 25 seeds per replication for the embryo elongation measurements. However, 30 seeds were initially imbibed, since a few seeds may have been damaged during the cutting step. Ten minutes were required per replicate for the cutting operation; therefore, the addition of water and cutting was staggered.

Data analysis. Germination speed $\left(\mathrm{T}_{50}\right)$ and uniformity $\left(\mathrm{T}_{\mathrm{sd}}\right)$ data were calculated from parameters describing the germination curves. These parameters were obtained for each repetition of each treatment by performing a standard nonlinear curve fit using the ordinary logistic model of the general computer pro- gram for statistical analysis, GENSTAT. The logistic model is given by:

$$
g=a+\frac{c}{1+e^{-b(t-m)}}+\varepsilon
$$

where $g$ is the percentage of seeds germinated at time $\mathrm{t}$ (GENSTAT, 1987). Means and standard errors of the mean were calculated for the $\mathrm{T}_{50}$ and $\mathrm{T}_{\mathrm{sd}}$ data. The parameters $\mathrm{a}, \mathrm{c}, \mathrm{b}$, and $\mathrm{m}$ were used to calculate the $\mathrm{T}_{50}$ and $\mathrm{T}_{\mathrm{sd}}$ as follows:

$$
\begin{aligned}
& T_{50}=-\frac{1}{b} \ln \left(\frac{c+a}{c-a}\right)+m \\
& T_{s d}=-\frac{1}{b}\left\{\ln \left[\frac{c+a}{5 c-a}\right]-\ln \left[\frac{5(c+a)}{c-5 a}\right]\right\}
\end{aligned}
$$

The embryo growth curves from the elongation test did not lend themselves well to an ordinary logistic model. Instead, 5-h elongation data was estimated by interpolating between data points for each repetition of each treatment. Experimental design was a randomized complete-block design with a $2 \times 4$ factorial (two priming $\times$ four aging periods). Least significant differences and trend analysis were performed on 5-h elongation data using the SAS General Linear Models Procedure.

\section{Results and Discussion}

Seed materials and aging. Non-primed and primed lettuce seeds were equilibrated at $50 \%$ $\mathrm{RH}$ prior to storage. The moisture content was
$6.34 \%$ and $6.42 \%$ (fresh-weight basis) for non-primed and primed seeds, respectively. The slightly higher seed moisture content of primed seeds has been reported previously for Vigna radiata (Sun et al., 1997). Sun et al. (1997) postulated that water binding was altered by priming, thus shifting the equilibrium moisture contents to higher values in region II. A higher seed moisture content is one factor responsible for faster aging in storage. However, using the Ellis-Robert's equations (Dickie et al., 1990), a $0.08 \%$ increase in seed moisture content would have only a small influence on longevity.

Germination tests. Non-primed and primed seeds were aged up to $21 \mathrm{~d}$ in 7 -d increments. Germination (radicle emergence) was $>98 \%$ for all treatments (data not shown), thus indicating that aging had little effect on total or final germination. The germination speed $\left(\mathrm{T}_{50}\right)$ was influenced by the interaction of priming and aging duration (Fig. 1A). Non-aged, primed seeds germinated faster than non-aged, nonprimed seeds, illustrating the beneficial effect of priming even under ideal germination conditions. Aging delayed germination (increased $\mathrm{T}_{50}$ ) regardless of priming treatment. However, primed seeds exhibited a greater increase in $\mathrm{T}_{50}$ with aging than did non-primed seeds. Germination uniformity was calculated as the time for one standard deviation of the seeds to germinate $\left(\mathrm{T}_{\mathrm{sd}}\right)$. The $\mathrm{T}_{\mathrm{sd}}$ values followed a similar trend to the $\mathrm{T}_{50}$ (Fig. 1B), revealing that aging decreased germination uniformity to a greater extent in primed than in non-primed
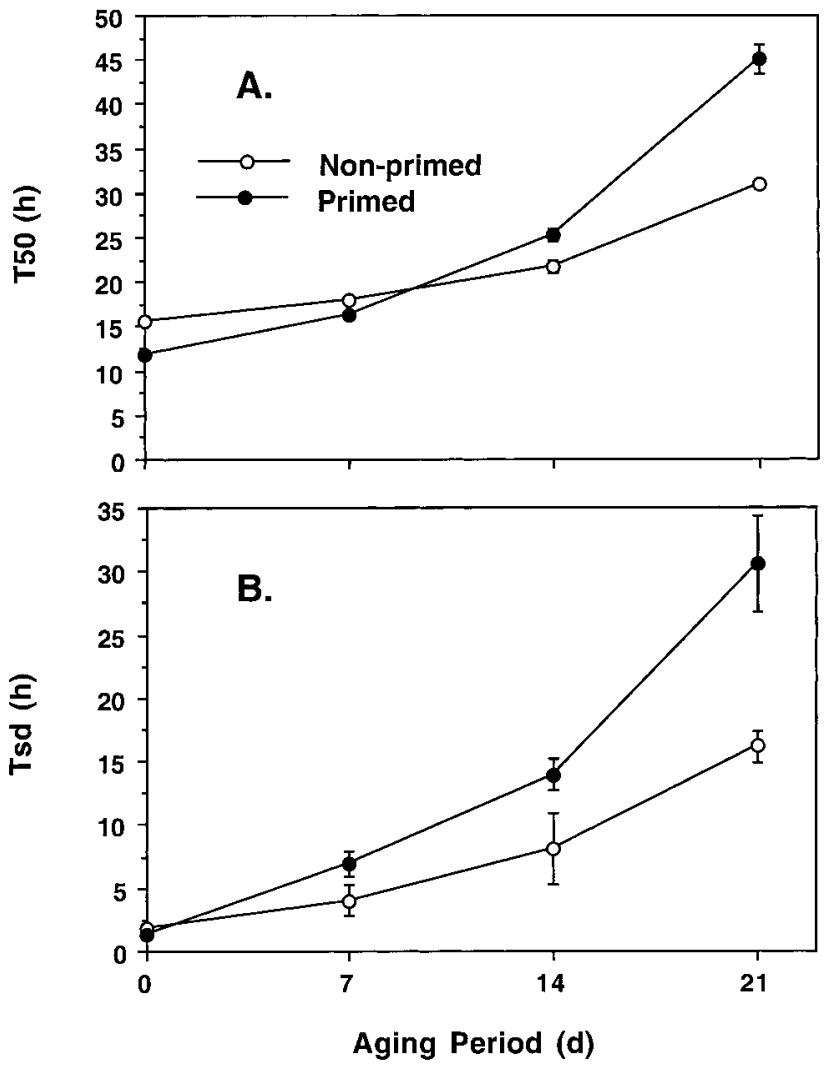

Fig. 1. The effects of priming and aging lettuce seeds on $(\mathbf{A})$ germination speed $\left(\mathrm{T}_{50}\right)$ and $(\mathbf{B})$ germination uniformity $\left(\mathrm{T}_{\mathrm{sd}}\right)$. Means with standard errors. 
seeds. The 21-d aged, primed seeds had larger $\mathrm{T}_{50}$ and $\mathrm{T}_{\mathrm{sd}}$ values than did all other treatments. For each priming treatment, $\mathrm{T}_{50}$ values were positively correlated with $\mathrm{T}_{\text {sd }}$ values $\left(r=0.99^{* *}\right)$. Our results are consistent with other studies on lettuce in which priming increased the aging rate (Tarquis and Bradford, 1992). In summary, germination rates as measured by both germination speed $\left(\mathrm{T}_{50}\right)$ and uniformity $\left(\mathrm{T}_{\mathrm{sd}}\right)$ were sensitive indicators of the early phases of aging prior to a loss in total germination.

Water uptake and embryo elongation test. Water uptake curves were obtained to determine when seeds were fully imbibed, since seeds needed to be hydrated for the cutting phase of the embryo elongation test. Little difference in water uptake was measured between primed and non-primed seeds at each sampling time, and seeds were nearly fully imbibed after $3 \mathrm{~h}$ (Fig. 2). Water uptake was also accompanied by an increase in seed volume. Lettuce seeds can increase $>100 \%$ in both weight and volume during imbibition (Hill and Taylor, 1989).

Visible elongation of the embryo from the seed coverings was used as the criterion of growth. In this technique, the objective was to score embryo elongation that was attributed to embryo growth (cell elongation), while expansion of embryo tissue due to physical swelling during imbibition would confound measurements. Preliminary studies revealed that soaking seeds for $>2 \mathrm{~h}$ caused them to be damaged during the cutting procedure. However, if imbibition periods were too short, the embryo elongation occurred within an hour, which was attributed to physical swelling during imbibition. The 2-h soak was chosen as the optimal hydration period to avoid injury during cutting and to minimize "false" elongation caused by swelling.

Non-primed and primed seeds aged in 7-d increments were used in the embryo elongation test. The percentage of elongated embryos was calculated at hourly intervals, and treatment differences were clearly observed after a 5 -h hydration period ( 2 -h soak $+3 \mathrm{~h}$ on blotters). The main effects of priming and aging were significant, while the interaction was not (Table 1). Although priming increased the percentage of elongated embryos, aging duration, which reduced the percentage in a linear trend, was a more important factor. The relationships of germination rate and the embryo elongation test results are shown in Fig. 3. The $\mathrm{T}_{50}$ values revealed a greater sensitivity (increase) with aging than the embryo elongation test results, resulting in curvilinear relationships for both priming treatments. The effect of aging and seed coverings may explain the curvilinear relationship from non-primed seeds. Aging reduces embryo growth (Hacisalihoglu, 1997) and tolerance to stress (Association of Official Seed Analysts, 1983). Since seed coverings provide a physical barrier for the completion of germination, these tissues can be considered a stress that the radicle must overcome. Therefore, the most severe aging treatment ( $21 \mathrm{~d}$ ) would be most sensitive to the physical barrier of the seed coverings, resulting in a retardation in germination. Priming

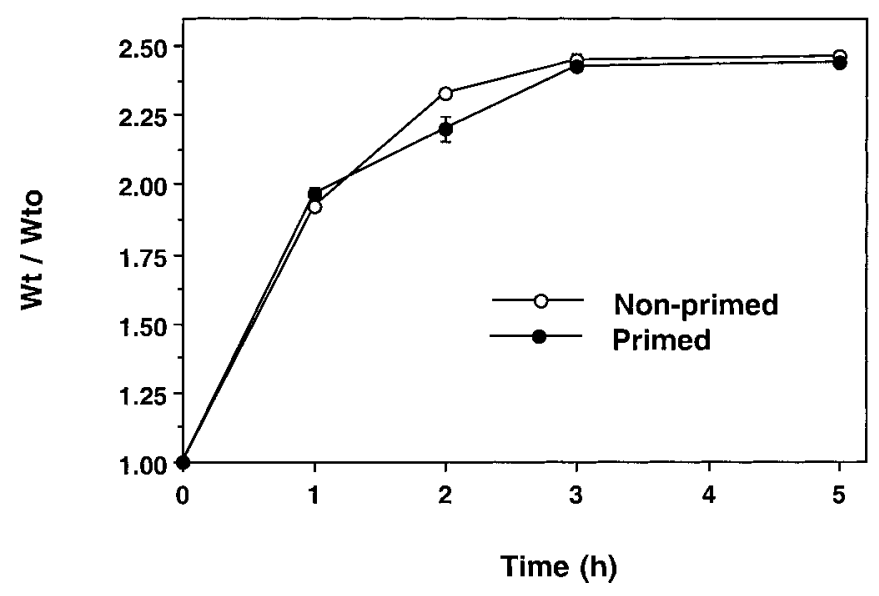

Fig. 2. Effect of priming on water uptake for 0 to $5 \mathrm{~h}$. Wto = weight before imbibition. Means with standard errors.

Table 1. The effect of aging and priming on percentage of elongated embryos after a 5-h hydration period.

\begin{tabular}{lccc}
\hline \hline \multirow{2}{*}{$\begin{array}{l}\text { Aging period } \\
\text { (days) }\end{array}$} & \multicolumn{3}{c}{ Elongated embryos (\%) } \\
\cline { 2 - 4 } & Non-primed & Primed & Mean \\
\hline 0 & 86 & 95 & 91 \\
7 & 79 & 80 & 79 \\
14 & 65 & 72 & 68 \\
21 & 48 & 59 & 53 \\
Mean & $69 \mathrm{~b}^{\mathrm{z}}$ & $77 \mathrm{a}$ & $\mathrm{L}^{* * * *}$
\end{tabular}

${ }^{2}$ Mean separation by LSD $(P \leq 0.05)$.

${ }^{* * *}$ Effects of aging significant at $P \leq 0.001$.

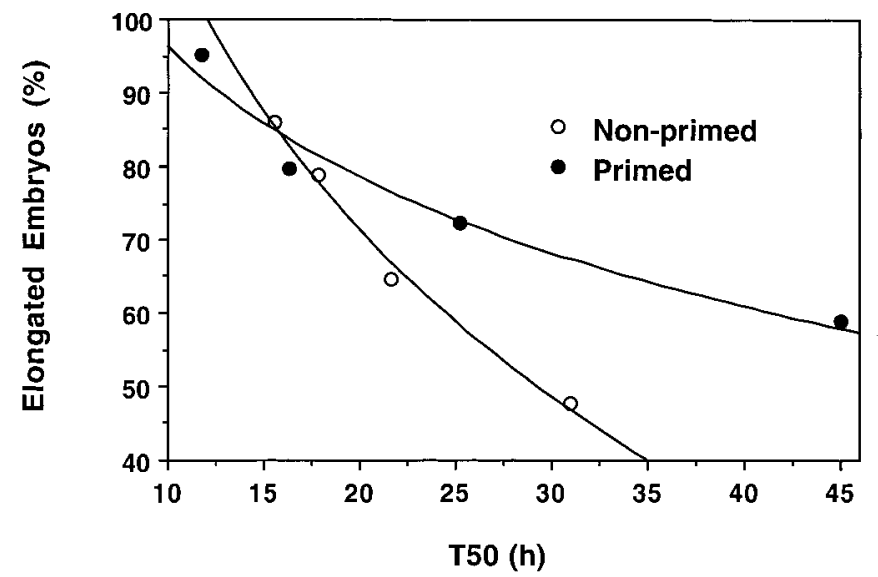

Fig. 3. Relationship of germination speed $\left(\mathrm{T}_{50}\right)$ vs. percent elongated lettuce embryos after a 5 -h hydration period.

further increased the deviation from linearity (Fig. 3). Aging and seed covering effects alone do not explain this observation. Priming has two separate effects; it enhances embryo growth rate (Hacisalihoglu, 1997) and accelerates the aging rate (Tarquis and Bradford, 1992). Therefore, priming augments deleterious effects of aging and results in greater sensitivity to the stress imposed by the seed coverings, culminating in a further delay of germination.

Merits of the embryo elongation test. Extensive measurements of embryo elongation rates conducted in time course studies were performed on enhancement treatments, aging and dormancy (Hacisalihoglu, 1997; Hacisalihoglu and Khan, 1998). These earlier studies showed that embryo growth was an excellent tool to assess seed quality. However, a simpler, faster, and less tedious method was needed for routine use. The embryo elongation test is a modification of the embryo growth time course method that does not require sophisticated equipment and can be performed in an 8-h work day. It produces objective data that are related to germination rate, a proven indicator of seed quality. The embryo elongation test provided a method to separate the individual (main) effects of priming and aging on embryo elongation (Table 1). Further research is needed to adapt this method to other species. The effect of selected treatments on embryo growth can be examined, without the influence of the seed coverings. 


\section{Literature Cited}

Association of Official Seed Analysts. 1983. Seed vigor testing handbook, Association of Official Seed Analysts, Contribution No. 32.

Dickie, J.B. , R.H. Ellis, H.L. Kraak, K. Ryder, and P.B. Tompsett. 1990. Temperature and seed storage longevity. Ann. Bot. 65:197-204.

GENSTAT 5 Committee. 1987. GENSTAT 5 reference manual. Oxford, New York, p. 366.

Hacisalihoglu, G. 1997. Effects of priming, dormancy and aging on embryo growth potential and germination of tomato and lettuce seeds. MS Thesis, Cornell Univ., Ithaca, N.Y.

Hacisalihoglu, G. and A.A. Khan. 1998. Factors influencing tomato and lettuce seed dormancy, p. 1-9. In: A.G. Taylor and X-L Huang (eds.). Progress in seed research: Proc. Second Intl. Conf. Seed Sci. and Tech. Communication services of the New York State Agr. Expt. Sta., Geneva, N.Y.

Hill, H.J. and A.G. Taylor. 1989. Relationship be- tween viability, endosperm integrity and imbibed lettuce seed density and leakage. HortScience 24:814-816.

Howarth, M.S. and P.C. Stanwood. 1993. Measurement of seedling growth rate by machine vision. Trans. Amer. Soc. Agr. Eng. 36:959-963.

International Seed Testing Association. 1996. International rules for seed testing. Seed Sci. Technol. 24(Supplement).

Khan, A.A. 1992. Preplant physiological seed conditioning, p. 131-181. In: J. Janick (ed.). Hort. Rev. Wiley, New York.

Parera, C.A. and D.J. Cantliffe. 1994. Presowing seed priming, p. 109-141. In: J. Janick (ed.) Hort. Rev. Wiley, New York.

Priestley, D.A. 1986. Seed aging implications for seed storage and persistence in the soil. Comstock, Ithaca, N.Y.

Sun, W.Q., D.C.Y. Koh, and C.M. Ong. 1997. Correlation of modified water sorption properties with the decline of storage stability of osmotically-primed seeds of Vigna radiata
Wilczek. Seed Sci. Res. 7:391-397.

Tarquis, A.M. and K.J. Bradford. 1992. Prehydration and priming treatments that advance germination also increase the rate of deterioration of lettuce seeds. J. Expt. Bot. 43:307-317.

Taylor, A.G. 1997. Seed storage, germination and quality, p. 1-36. In: H.C. Wien (ed.). The physiology of vegetable crops. CAB, Wallingford, U.K.

Taylor, A.G., P.S. Allen, M.A. Bennett, K.J. Bradford, J.S. Burris, and M.K. Misra. 1998. Seed enhancements. Seed Sci. Res. 8:245-256.

Taylor, A.G., D.F. Grabe, and D.H. Paine. 1997. Moisture content and water activity of pelleted and film-coated seeds. Seed Tech. 19:24-32.

Tomas, T.N., A.G. Taylor, and L.A. Ellerbrock. 1992. Time-sequence photography to record germination events. HortScience 27:372.

Valdes, V.M. and K.J. Bradford. 1987. Effects of seed coating and osmotic priming on the germination of lettuce seeds. J. Amer. Soc. Hort. Sci. 112:153-156. 